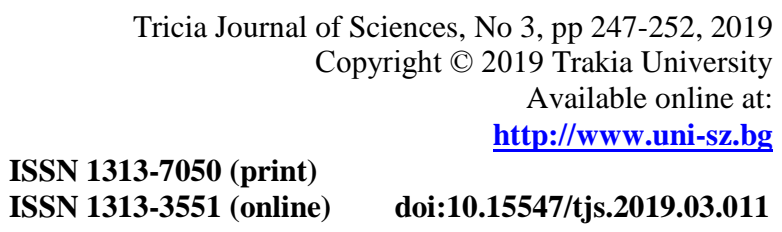

Original Contribution

\title{
CORRELATION BETWEEN RESULTS OF FUNCTIONAL LORDOSIS TEST AND DIGITAL PELVIC INCLINOMETER
}

\author{
K. Kolev, R. Tasheva* \\ Physical Therapy Department - Theory and Methodology of the Physical Therapy National Sports \\ Academy "Vassil Levski"- Sofia, Bulgaria
}

\begin{abstract}
THE AIM of this study is to precise the diagnostics of lumbar lordosis in children at primary classes through applying the Digital Pelvic Inclinometer and to correlate the results with the Functional Test. METHODS. The screening examination involved 132 children with the average age 8,7 from the beginning classes in Sofia. The lumbar lordosis was assessed through the Fuctional Test in all children during the period April - June 2016.. The DPI was applied for preliminary investigation in 25 children of measuring left and rigth pelvic inclination and therefore - torsion. RESULTS. The lordosis test is negative in 8 children and 16 are with functional lordosis. The mean value of the test with DPI - left sided, for healthy children is 7.1 degrees, and in children with functional lordosis is $10.9^{0}$. The difference of $3.8^{0}$ is statistically significant due to the value of T-Student criterion $(\mathrm{t})$ of 2.63 at a critical value of 2.07. CONCLUSION. The results showed the correlation between the Digital Pelvic Inclinometer Test and the Functional Lordosis Test. This study confirmed that the applying of the Digital Pelvic Inclinometer give an opportunity to precise the diagnostics of lumbar lordosis in children.
\end{abstract}

Key words: Digital Pelvic Inclinometer, lordosis

\section{INTRODUCTION}

Postural disorders of the spine are significantly prevalent among children. A large percentage of them are in the sagittal plane and with localization in lumbar spine. Usually we apply the functional test for the assessing lordosis (1). In the last years, our research found that the functional lordosis is not predominantly a feature of female children and this postural problem is extended also among primary schoolboys. Early and detailed functional diagnostics of lordosis with digital pelvic inclinometer (DPI) will help to precise the diagnostic and programming physiotherapy. This is the rationale for our study.

THE AIM of this study is to precise the diagnostics of lumbar lordosis in children at primary classes through applying the Digital

\footnotetext{
*Correspondence to: Rumiana Tasheva, National Sports Academy "Vassil Levski”- Sofia, Bulgaria, Tel: 08933965 83; e-mail: rumiana_tasheva@yahoo.com
}

Pelvic Inclinometer and to correlate the results with the Functional Test.

\section{METHODS}

Subject

The screening examination involved 132 children (62 girls and 70 boys) with the average age 8,7 (from 7 to 9 years) from the beginning classes (from I to III classes) at the School "Iordan Iovkov" - Sofia. The lumbar lordosis was assessed through the Fuctional Test in all children during the period April June 2016.. The DPI was applied for preliminary investigation in 25 children of measuring left and rigth pelvic inclination and therefore - torsion.

\section{Procedure}

In beginning we check the lower back in the sagittal plane for the presence of excessive lordosis - this is view of the back. After this, a bilateral Test in standing position with hip and knee flexion in $90^{\circ}$ was applied to determine the type of lordosis. Finally, the inclination of 
innominate bones and torsion of the pelvic in standing position was evaluated with DPI. Both lower limbs were examined.

The next indexes were registered in: surgery; pulmonary disorders; infectious diseases; cardiovascular disease, scars, congenital anomalies and more.

\section{Assessment}

\section{Inspection}

During normal standing position with heels brought together, fingers pointing outward, knees are extended and upper limbs are freely granted to the body. Body and head are in the normal upright position without the additional stress of back and abdominal muscles. The level of superior anterior iliac spine and superior posterior iliac spine were inspected from the front, side and back (Figure 1) (2).

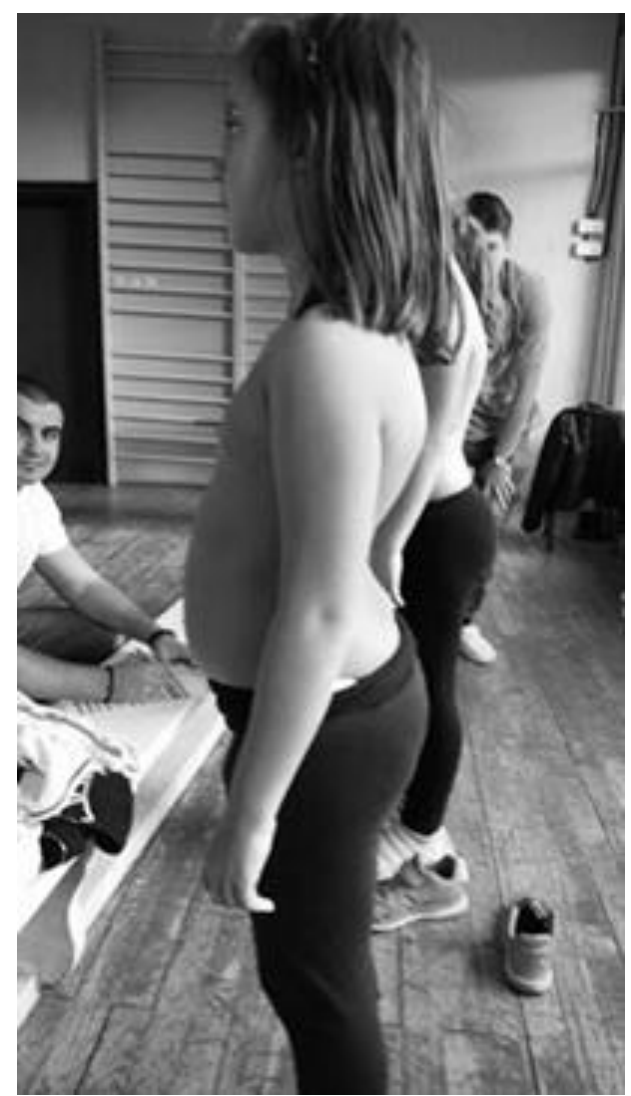

Figure 1. Inspection of the lumbar back from side
KOLEV K. et al.

\section{Functional Test determining the type of $\underline{\text { Lordosis }}$}

Standing is a start position. When running the test the leg of the evaluated children is placed in $90^{\circ}$ hip and knee flexion and holds this position for a few seconds. Screen whether lumbar lordosis by hip flexion is flattened. If the arch smooth define as a functional lordosis, if does not as a structural lordosis (Figure 2). The test is performed consecutively with both lower limbs. (2).

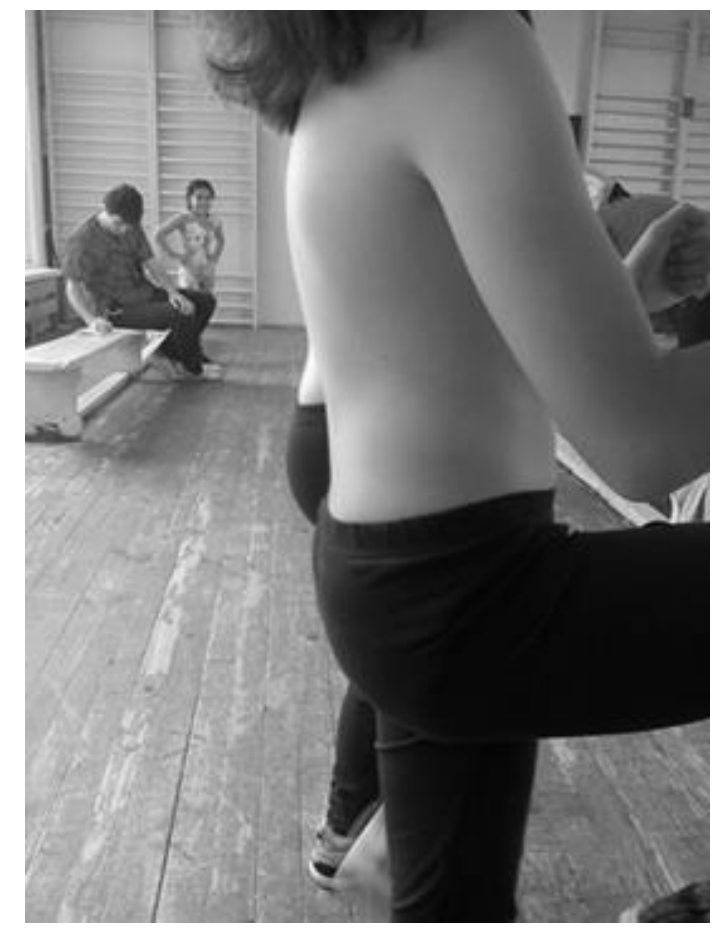

Figure 2. Determining the type of lordosis

\section{Basic Pelvic Torsion Measurement-DPI $\underline{\text { test }}$}

Start on one side of the child and take an innominate bone inclination. Then repeat the innominate bone inclination measurement, but this time on the contralateral side. (Figure 3) Any difference in the values between each side is described as a pelvic torsion, which may require corrective treatment (Table 1). $(3,4)$.

Table 1. An example of a basic pelvic torsion measurement

\begin{tabular}{|l|l|}
\hline Right innominate inclination & $15^{0}$ \\
\hline Left innominate inclination & $8^{0}$ \\
\hline Pelvic Torsion & $7^{0}$ \\
\hline
\end{tabular}




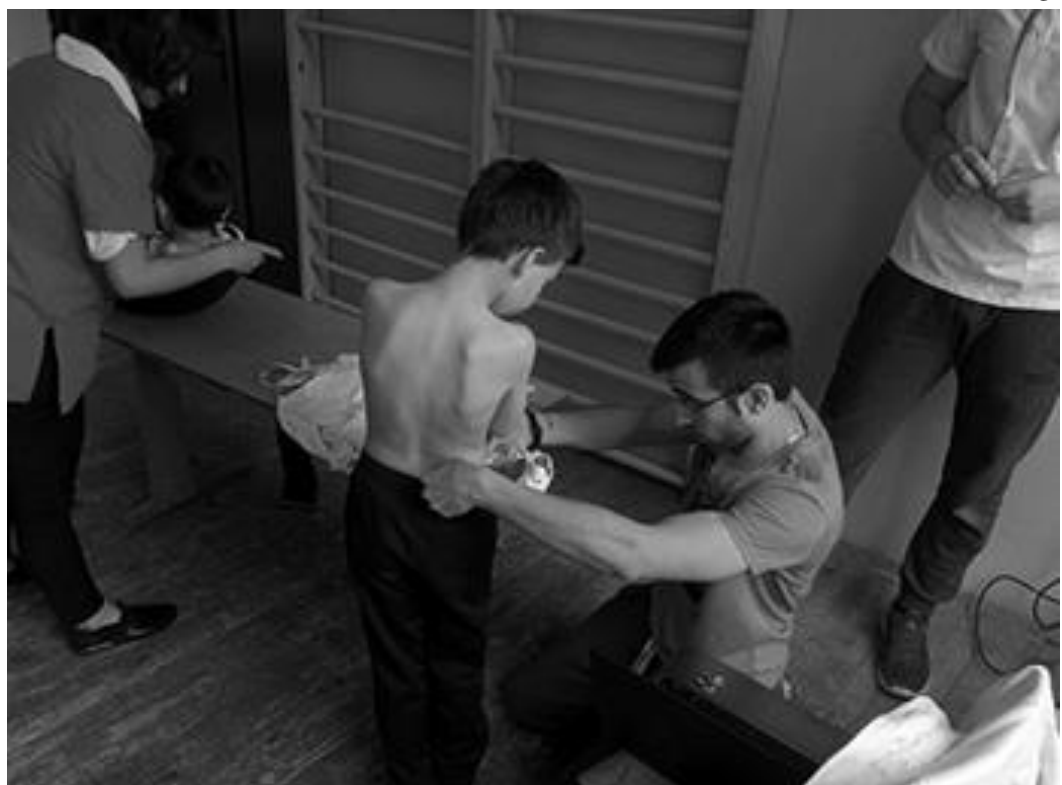

Figure 3. Pelvic torsion measurement - DPI test

The center of mass (CoM) passes anterior to the sacral base and ankle joint, slightly posterior of the acetabulum but just anterior to the thoracic spine and knees. The anterior superior iliac spine (ASIS) and pubic symphysis are aligned vertically (Figure 4). In

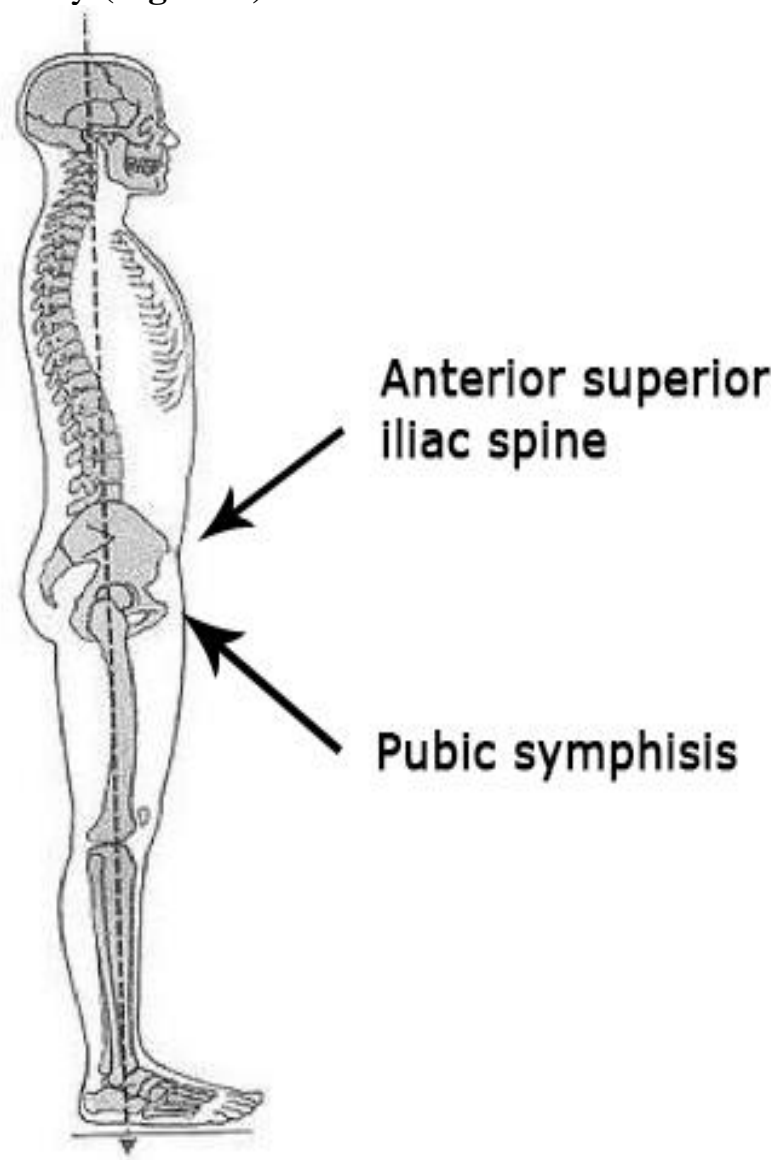

Figure 4. The normal standing upright posture this position the pelvis is in 'neutral' and is described as an "ideal position for the pelvis". This author describes the normal inclination of the average adult innominate to be around 8 to $10^{\circ}+\mathrm{ve}$, based on clinical experience (5).

\section{RESULTS}

From the totally tested 25 children 15 are girls and 10 boys. Children with indicated increased lordosis are $17(68 \%)-11(73.35 \%)$ girls and
$6(60 \%)$ boys. Then healthy children are 4 (26.6\%) from the 15 girls and $4(40 \%)$ from the boys (Table 2). 
Table 2. Results from lordosis functional test

\begin{tabular}{|l|c|c|c|}
\hline Gender & $\mathbf{N}$ & $\begin{array}{c}\text { Children with } \\
\text { lordosis }\end{array}$ & Healthy Children \\
\hline Females & $15(60 \%)$ & $11(73.35 \%)$ & $4(26.6 \%)$ \\
\hline Males & $10(40 \%)$ & $6(60 \%)$ & $4(40 \%)$ \\
\hline Total & $\mathbf{2 5 ( 1 0 0 \% )}$ & $\mathbf{1 7 ( 6 8 \% )}$ & $\mathbf{8 ( 3 2 \% )}$ \\
\hline
\end{tabular}

The conclusions of Table 3 are as follows:

- Children with functionally increased lordosis innominate inclination values range from left side $-4.20^{\circ}$ to $22.50^{\circ}$ and right side $-3.50^{\circ}$ to $18^{\circ}$

Table 3. Descriptive statistic for pelvic tilt
- Healthy children innominate inclination values range from left side $-4.50^{\circ}$ to $11.70^{\circ}$ and right side $-3.50^{\circ}$ to $10.60^{\circ}$

- Pelvic torsion range in functionally increased lordosis children $-0.50^{\circ}$ to $9.30^{\circ}$ and healthy children range is $0.00^{\circ}$ to $1.10^{\circ}$

\begin{tabular}{|l|c|c|c|c|c|c|c|c|c|c|}
\hline \multicolumn{1}{|c|}{ Index } & Side & $\mathbf{N}$ & $\mathbf{X m i n}$ & $\mathbf{X m a x}$ & $\mathbf{R}$ & $\overline{\mathbf{x}}$ & $\mathbf{S}$ & $\mathbf{V}$ & $\mathbf{A s}$ & $\mathbf{E x}$ \\
\hline \multirow{2}{*}{$\begin{array}{l}\text { Children with } \\
\text { lordosis }\end{array}$} & Left & 17 & 4.20 & 22.50 & 18.30 & 11.02 & 4.22 & 17.80 & 1.16 & 2.51 \\
\cline { 2 - 11 } & Right & 17 & 3.50 & 18.00 & 14.50 & 10.95 & 3.63 & 13.20 & -0.10 & 0.67 \\
\cline { 2 - 10 } & Torsion & 17 & 0.50 & 9.30 & 8.80 & 2.78 & 2.43 & 5.93 & 1.51 & 1.06 \\
\hline \multirow{2}{*}{$\begin{array}{l}\text { Healthy children } \\
\text { children } \\
\text { without lordosis) }\end{array}$} & Left & 8 & 4.50 & 11.70 & 7.20 & 8.76 & 2.41 & 5.79 & 0.40 & -0.79 \\
\cline { 2 - 10 } & Right & 8 & 3.50 & 10.60 & 7.10 & 8.14 & 2.41 & 5.80 & -0.05 & -1.08 \\
\cline { 2 - 10 } & Torsion & 8 & 0.00 & 1.10 & 1.10 & 0.62 & 0.4 & 0.16 & -0.80 & 1.5 \\
\hline
\end{tabular}

- The study groups are sufficiently uniform performance DPI test, as the coefficient of variation $(\mathrm{V})$ is $17.80 \%$ of left side and $13.20 \%$ of right side for children with established functionally increased lordosis and $5.79 \%$ of left side and $5.80 \%$ of right side for healthy children. Torsion variation in children with lordosis is $5.93 \%$ and $0.16 \%$ for healthy children. Coefficients are close to those of highly homogeneous sample (Table 3).

- Coefficients of skewness (As) and kurtosis (Ex) are, respectively, for children with

\section{increased lordosis As 1.16(left) -} 0.10 (right)- Ex 2.51 (Left) and Ex 0.67 (right) at $\alpha=0,05$ and healthy children - As 0, 40 (left) -0.05 (right )and Ex -0.79 (left) 1.08 (right) at $\alpha=0,05$ are below critical, which means that the criterion has a normal distribution.

- Torsion values: children with increased lordosis - As 1.51, Ex 1.06; healthy children - As-0.80 Ex 1.5 at $\alpha=0,05$

The correlation with standards on the left and right side is presented in Table 4.

Table 4. Values according to norms

\begin{tabular}{|c|l|l|l|l|l|l|l|}
\hline & $\mathbf{N}$ & \multicolumn{2}{|c|}{ In standards } & \multicolumn{2}{c|}{ Excess (+) } & \multicolumn{2}{c|}{ Subnorm (-) } \\
\cline { 2 - 8 } & & Left & Right & Left & Right & Left & Right \\
\hline $\begin{array}{c}\text { Children with } \\
\text { lordosis }\end{array}$ & $17(100 \%)$ & $6(35,3 \%)$ & $1(5,9 \%)$ & $8(47,05 \%)$ & $13(76,47)$ & $2(11,76 \%)$ & $3(17,64 \%)$ \\
\hline $\begin{array}{c}\text { Healthy children } \\
\text { children without } \\
\text { lordosis) }\end{array}$ & $8(100 \%)$ & $2(25 \%)$ & $2(25 \%)$ & $1(12,5 \%)$ & $1(12,5 \%)$ & $5(62,5 \%)$ & $5(62,5 \%)$ \\
\hline Totall & $25(100 \%)$ & $8(32 \%)$ & $3(12 \%)$ & $9(36 \%)$ & $14(56 \%)$ & $7(28 \%)$ & $8(32 \%)$ \\
\hline
\end{tabular}

From this analysis we can see the percentage of values according to the standards both groups from left and right side measured in children. (Chart 1) 


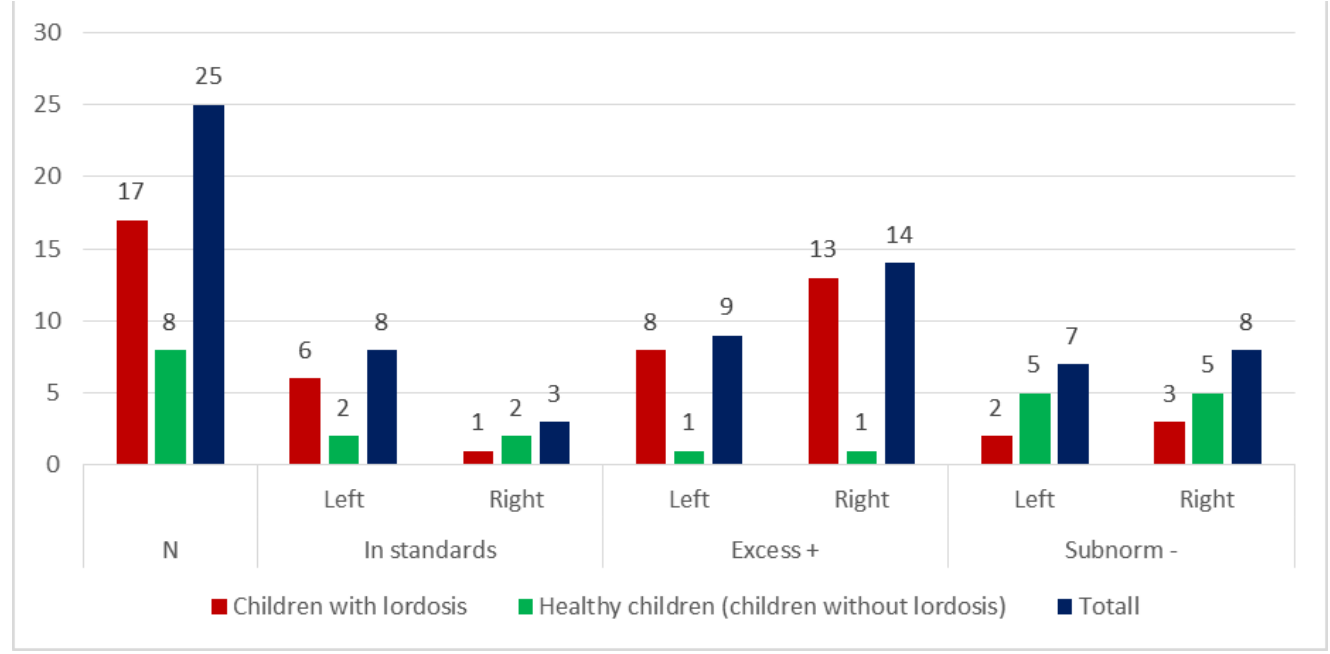

Chart 1. Diagram of values according to norms

Table 5. Dependence between the type of lordosis and pelvic inclination

\begin{tabular}{|c|c|c|c|c|c|c|c|c|c|c|c|}
\hline \multirow{2}{*}{ Index } & \multirow{2}{*}{ Sign } & \multicolumn{3}{|c|}{ Healthy children } & \multicolumn{3}{|c|}{$\begin{array}{c}\text { Functional } \\
\text { lordosis }\end{array}$} & \multicolumn{4}{c|}{ Statistical } \\
\cline { 2 - 12 } & & $\mathbf{n 1}$ & $\mathbf{X 1}$ & $\mathbf{S 1}$ & $\mathbf{n 2}$ & $\mathbf{X 2}$ & $\mathbf{S 2}$ & $\mathbf{t}$ & $\mathbf{P}(\mathbf{t})$ & $\mathbf{d}$ & rpb \\
\hline \multirow{2}{*}{ Lordosis } & Left inclination & 8 & 8,7 & 2,4 & 16 & 10,9 & 3,7 & 2,63 & 98,5 & 3,8 & 0,489 \\
\cline { 2 - 12 } & Torsion & 8 & 0,6 & 0,4 & 16 & 0,07 & 1,7 & 2.44 & 97,7 & 1,5 & 0.461 \\
\hline
\end{tabular}

By IBM SPSS statistics analysis, we made correlation between parametric and nonparametric values from both tests. (6).

The Lardosis Test is negative for 8 children, 16 with functional lordosis, and one with structural lordosis. The mean value of the test with DPI - left sided, for healthy children is 8,7 degrees, and in children with functional increased lordosis is $10.9^{0}$. The difference of $3.8^{0}$ statistically significant due to the value of T-Student criterion $(\mathrm{t})$ of 2.63 at a critical value of 2.07 (24 respondents) and warranty probability is $98.5 \%$. Biserial factor ( $\mathrm{rpb})$ is above the critical value of 0.49 , which means that belonging to groups "healthy children" and "children with functional increased lordosis" influences signs "left-sided inclination of the pelvis" (Table 5).

Torsion in healthy (normal lordosis) children means 0.7 degrees and in the other with functionally increased lordosis is 2.2 degrees. The difference (d) from 1.5 degrees statistically significant because the value of the T-criterion $(\mathrm{t})$ of 2.44 , which is above the critical value -2.07 and guaranteed probability of $97.7 \%$ and the value of biserial factor 0.461 above critical of 0.39 , which means that belonging to groups "healthy persons" and "persons with functional lordosis" influences signs "left-sided inclination of the pelvis".

\section{DISCUSSION}

If we consider the author Kendall, and its values for standard inclination of the pelvis, then our studies DPI average group of children with established functionally increased lordosis are left $11.02^{\circ}$ - right $10.95^{\circ}$, and the group of healthy children $-8.76^{\circ}$ left side and $8.14^{\circ}$ for right side. (Table 3)

As it means that, if $10^{\circ}$ for the maximum value of the norm, it is from these results it is clear that the group of children with functionally increased lordosis are $1.02^{\circ}$ above the norm of the left side, and $0.76^{\circ}$ on the right side. However, if the results of STI were compared in this study between healthy children and children with functionally enlarged lumbar lordosis, significant differences were noted: left-handed -2.26 and right-handed -2.81 .

From the results in healthy children establish normal values for the inclination of the pelvis.

\section{CONCLUSION}

The results showed the correlation between the Digital Pelvic Inclinometer Test and the Functional Lordosis Test. This study confirmed that the applying of the Digital Pelvic Inclinometer contribute very important data and give an opportunity to precise the diagnostics of lumbar lordosis in children at primary classes. 


\section{Abbreviations:}

DPI - Digital Pelvic Incllinometer

CoM - Center of mass

ASIS - anterior superior iliac spine

\section{REFERENCES}

1. Tasheva, R., Kolev, K., Detailed Functional Diagnostic in Lumbar Lordosis Through Hamstring Length Test. 9 th FIEP European Congress 7 th International Scientific Congress "Sport, Stress, Adaptation" Physical education and Sport Competences for Life. Books of abstracts, Journal sports and science, extra issue, ISSN 1310-3393, 4, NSA "Vassil Levski", Sofia. pp 48-49, 2014.
2. Tasheva, R., Lectures and seminars of functional diagnostic and physiotherapy in spine and chest deformities. Physiotherapy Faculty, National Sports Academy "Vasil Levski", Sofia, 2008.

3. Clifton, B., Sub-4 Technologies. Section A posture-A basic guide to pelvic position, 2013.

4. Clifton, B., Sub-4 Technologies. Section B operation of the DPI, 2013.

5. Kendall, F., McCreary, E., Muscles testing and Function with Posture and Pain \& Lippincott, 2005.

6. Damyanova, R., Gigova, V., Statistical methods in sport. Student guide for bachelors. National Sports Academy "Vassil Levski", Sofia, 2000. 